\title{
Dr Earl Stuart Russell
}

\author{
Patricia K Morley-Forster MD FRCPC
}

$\mathrm{D}_{\mathrm{r}}^{\mathrm{s}}$ Earl Russell, a physician who dedicated most of his professional life to the alleviation of pain, passed away peacefully in his home on October 12, 2008, at the age of 88 years. Over the past 10 years, he donated more than $\$ 2.5$ million to the University of Western Ontario Schulich School of Medicine and Dentistry (London, Ontario) to endow the Earl Russell Chair in Pain Management. This is one of the few such positions in North America and the only one in Canada. The current holder of the Earl Russell Chair, Dr Dwight Moulin, commented that "he made a huge difference at Western because the initiation of the [Earl Russell] Chair [in Pain Management] has increased our profile tremendously regarding pain research and management both nationally and internationally."

Earl Russell was raised on a farm in Saskatchewan and came of age during the Depression years. The young Russell obtained his high school diploma while working full time as a farmhand during his teenage years, a remarkable achievement. He was offered entrance to the undergraduate program in mathematics at the University of Saskatchewan (Saskatoon, Saskatchewan). His parents taught him to work hard and to be concerned about other people. These two principles were the foundation of his life and career.

Dr Russell served in World War II as an officer in the Royal Canadian Signal Corps. He returned after the war to study medicine, first at the University of Saskatchewan, then at the University of Western Ontario, graduating with his MD in 1950. Dr Russell first developed an interest in the treatment of pain while serving as a young medical officer in the Korean War. He was assigned to the 8055th Mobile Army Surgical Hospital, the unit that inspired the tremendously popular television series MASH. To ease the pain of soldiers suffering from frostbitten fingers, he taught himself how to do a stellate ganglion block, improving circulation and blocking pain. Many of his anesthesia and intensive care skills, vital to the survival of severely traumatized patients, were also self-taught.

After his discharge from the military, he underwent formal training in anesthesia at Kingston General Hospital, gaining his certification in the specialty in 1955. He was invited to become a member of the founding medical faculty in the University of Lagos, Nigeria, and worked there from 1962 to 1964 before returning to Queen's University (Kingston, Ontario).

In 1968, he was recruited to the University of Western Ontario specifically for his skills in chronic pain management and obstetric analgesia. Due to his influence, the provision of epidurals for the relief of labour pain became a well-established practice in the early 1970s in London, 15 years ahead of the practice becoming widespread in the rest of Ontario. He served as Chief of Anesthesia at Victoria Hospital and President of its Medical Staff Association. In 1982, Dr Russell retired from the University of Western Ontario having attained the rank of Professor Emeritus. However, in his 'retirement', he continued to run very busy pain clinics in Ingersoll and Newbury, Ontario four days a week until 2007.

In 2004, Dr Russell was awarded a Distinguished Lifetime Achievement Award from the Canadian Pain Society. In 2006, the University of Western Ontario awarded him an honorary Doctorate in Science. In his address to the convocation assembly, Dr Russell stated, "In our country, there is a desperate shortage of physicians in the field of pain medicine. Interestingly, this is now also a fast-growing area of medicine and I want my alma mater to lead the way."

He grew up working on a farm, and ran his own farm of approximately 60 head of cattle near London until 85 years of age. Amazingly, he still found time and energy to be heavily involved in church and community activities. One of his proudest accomplishments was chairing the committee that first brought Meals on Wheels to London seniors.

Dr Russell was a compassionate, caring physician who was also a visionary in recognizing the immense need for education and research in pain management. He is survived by his wife of 61 years, Marjorie (Midge), and four daughters, 11 grandchildren and five great-grandchildren.

Department of Anesthesia and Perioperative Medicine, University of Western Ontario and Schulich School of Medicine, London, Ontario 


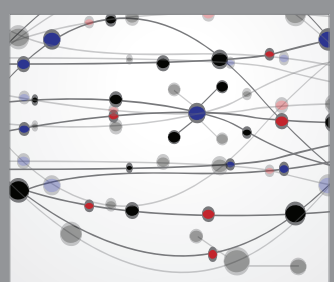

The Scientific World Journal
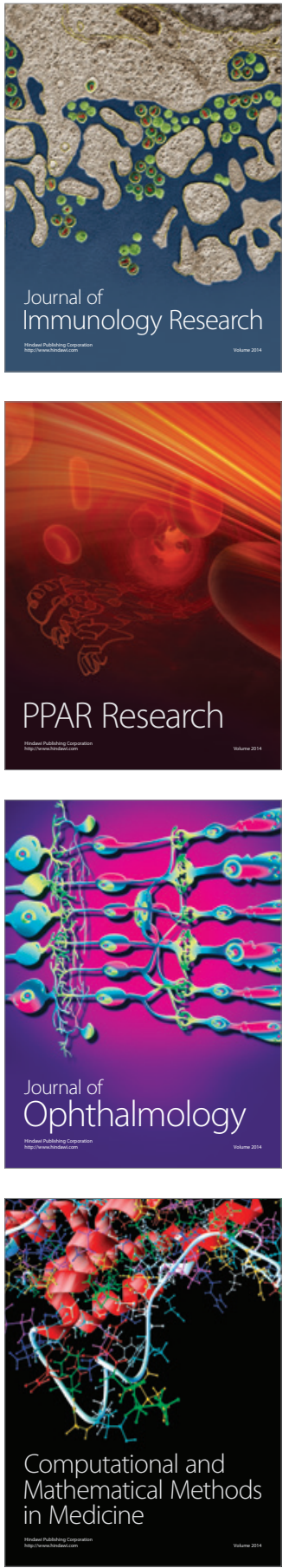

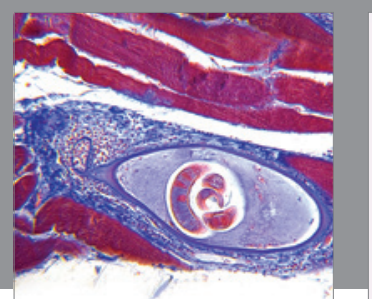

Gastroenterology Research and Practice

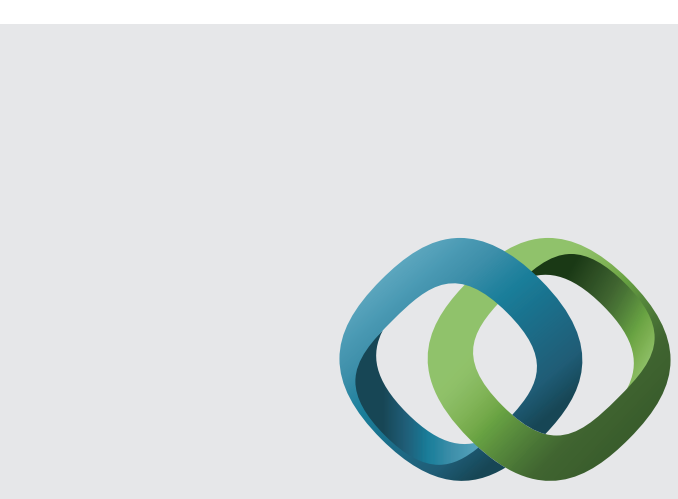

\section{Hindawi}

Submit your manuscripts at

http://www.hindawi.com
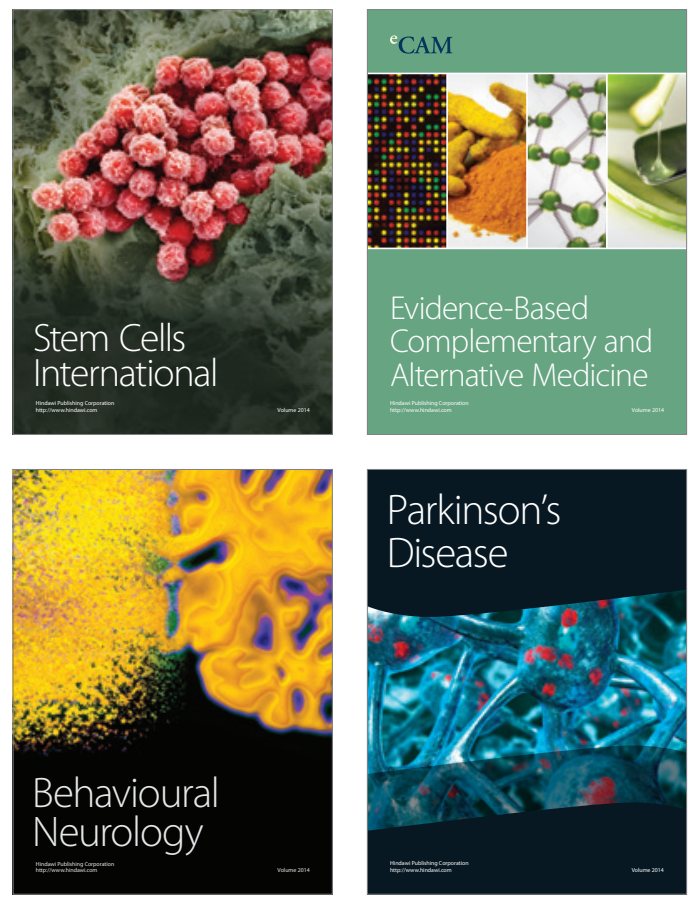
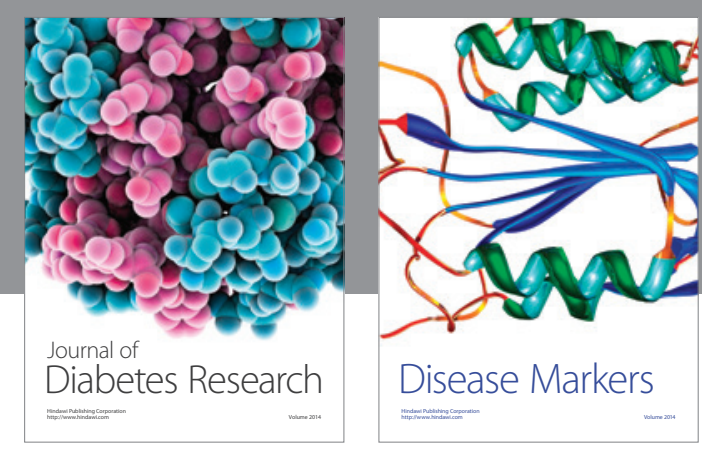

Disease Markers
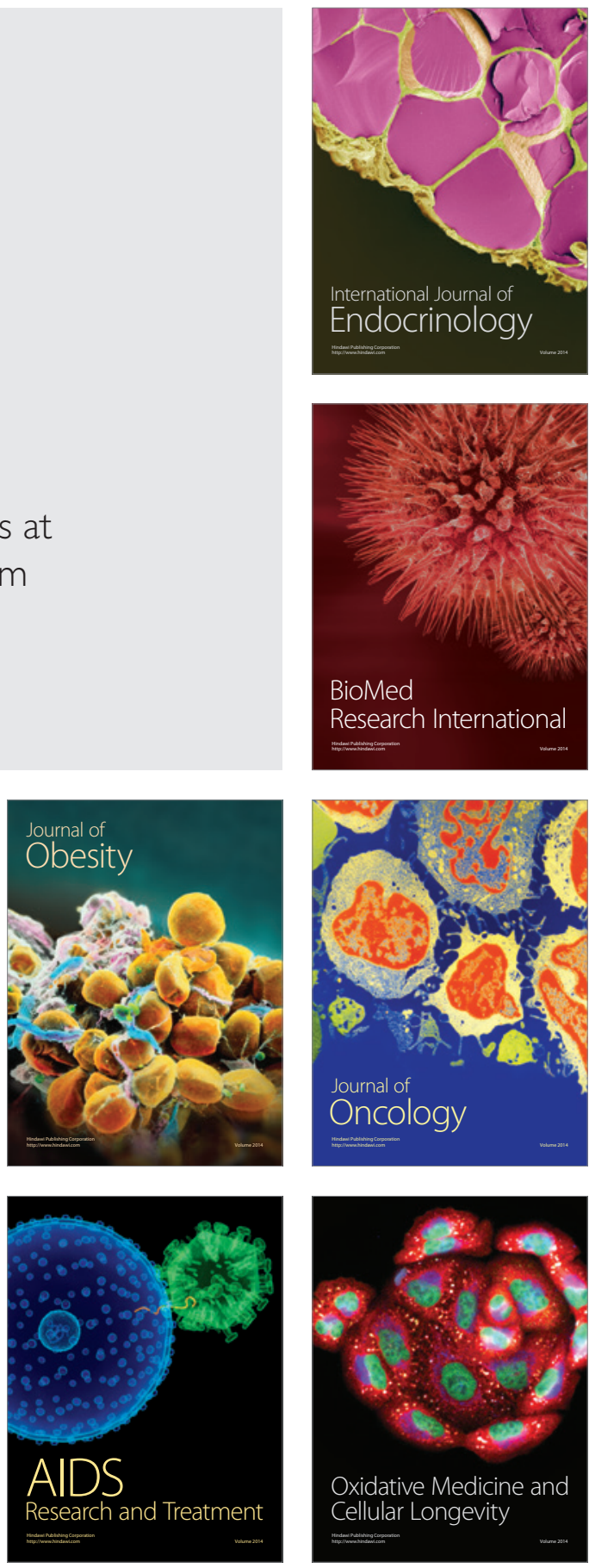